\title{
Israel Moiseevich Gelfand, Part II
}

\section{Vladimir Retakh, Coordinating Editor}

\section{Dusa McDuff}

\section{An Encounter with Gelfand}

I was Gelfand's student for six months in the winter of 1969-1970 and am very happy to have this opportunity to honor him. A great inspiration and source of strength for many years, he had a transformative effect on my career.

After undergraduate study at the University of Edinburgh, I had spent two years as a graduate student at Cambridge, solving a well-known problem about von Neumann algebras. My husband was writing a Ph.D. on Innokenty Annensky, a somewhat obscure but well-regarded Russian symbolist poet, and he needed to study in the Moscow Archives. My advisor suggested that I also apply for a British Council scholarship to Moscow, which I did, but he never suggested that I make a plan for what to do while there. So when I got to Moscow and was asked whom I wanted to study with, I was completely unprepared for the question. I said the first name that came to mind, which luckily was Gelfand. (I knew his name because some years earlier I had studied some of his books on distribution theory.) They called him up, and we arranged to meet. "How will I recognize you?" he asked. I explained what I looked like and he told me what he looked like. No doubt we met sometime just before his seminar.

He wanted to know why I was in Moscow (at that time there were not many foreign visitors)

Dusa McDuff is Helen Lyttle Kimmel '42 Professor of Mathematics at Barnard College, Columbia University. Her email address is dusa@math.columbia.edu.

The coordinating editor thanks Mark Saul for his help in the preparation of this collection.

DOI: http://dx.doi.org/10.1090/noti952 and I explained about my husband, David. He asked what I'd done, and I told him of my work in von Neumann algebras. He said, "Well, I am much more interested in the fact that David is studying Annensky than that you have solved this problem about von Neumann algebras." Then he gave me his recent paper on Gelfand-Fuchs cohomology to read. It was titled "The cohomology of the Lie algebra of vector fields on a manifold", but I had been so narrowly educated that I didn't know what cohomology was, what a Lie algebra was, what a vector field was, or what a manifold was.

So he told me what to do. I went to Kirillov's lectures on Lie groups (I could understand Russian but not speak it); I studied in the library-I remember reading a very well-thumbed copy of Eilenberg and Mac Lane and thinking how strange it was that I was reading this classic math book in English at a table in the Moscow University library; and of course I went to the seminar. That was wonderful. I gave a talk on my work, with Gelfand translating one of my English sentences followed by about ten of his Russian ones. He also talked to me before the seminar (he called it his English lesson) about all kinds of mathematics. He was trying to explain to me how certain ideas emerged, how they were interrelated. Of course I didn't understand very much at all, but I was amazed at the way he thought about what he was doing. He said, for example, that in some series of papers he'd been groping for an idea that didn't quite come into focus, so he tried again some years later with a completely different approach. I'd never imagined that mathematics might be thought of as anything other than a collection of definite, though perhaps very beautiful, theorems. 
One week he talked to me for over an hour before the seminar. People kept coming in and saying, "Come on, everyone's waiting." But he wanted to finish his explanations. I felt rather uncomfortable about this and made some excuse for the next week. That was obviously not the right thing to do, and I didn't see him for a while, until a few weeks later I gave him a translation that I had made of an article he'd written on biology and nature. "Why did you do this?" he asked. I think he was a bit suspicious of me, at that point. I said he'd asked me to translate it so I could send it to my father (who was a distinguished geneticist interested in the ideas of René Thom). Gelfand, of course, thought that René Thom had a completely wrong approach to biology and wanted his own views to be better known in the West. So by that translation I got back into his good graces. We resumed meeting, but not at the seminar. Instead, he occasionally invited me to his house.

I don't remember much of the mathematics he taught me then, though certainly we did talk about math. But I remember him reading Pushkin with me; he translated the play Mozart and Salieri for me, obviously thinking of himself as Mozart. He played some Bach records and made tea (I remember he had a treasure trove of little packets of special teas that people had sent him from all over Russia). He also invited my husband, David, to supper once or twice and told us stories about Mandelstam's widow (whom he'd known) and various Jewish anecdotes. Once he took me shopping: he bought and gave me all the good classical records he could find. Very cheap, they contained wonderful performances by Russian musicians that he thought I should hear. He said that this too was "teaching me mathematics." I was a would-be mathematician married to a would-be poet, and it was very important to me that he tried to reach me in this way.

When I got back to Britain, I had quite a difficult time. I'd completely changed my field and for several years didn't really have anyone to work with. But Gelfand kept in touch. He sent me New Year's cards, even occasionally with a brief personal note. He told people like Atiyah and Singer about me, and it was clearly on his recommendation that I spent a year at MIT, another very important milestone in my career. So he mentored me in every way he could. I visited Moscow again in 1983 (going for a week or so with the Haefligers and with Jack Milnor). I gave another talk at his seminar, but he thought the topic was uninteresting. Afterwards, he advised me to finish my papers and then move on. So I gradually moved towards symplectic geometry. I gave another talk at his seminar at Rutgers around 1995, and this one he did like.
I also remember that once we were in New York City together (I don't remember exactly when this was, but sometime before he moved here). He took me to the Frick Collection (which at that time I didn't know about) and showed me Rembrandt's selfportrait, how its eyes follow you as you walk around looking at it. I am sure he thought that Rembrandt was seeing him. But that's okay. I like people who have large ideas.

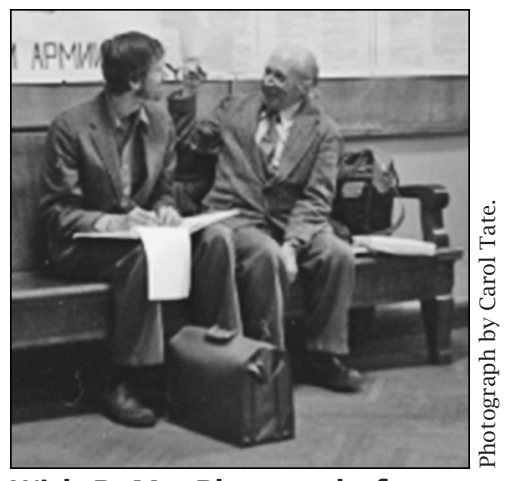

With R. MacPherson before the Monday night seminar, 1980.

\section{Vladimir Retakh}

\section{Israel Moiseevich Gelfand}

I spent many years in close association with Gelfand. Let me try to recall a few moments.

My first "interaction" with him started under circumstances that were unfortunate for me. At seventeen I came to the Moscow State University from the provinces to take the entrance examinations to the Department of Mechanics and Mathematics. I successfully passed my mathematics examinations but failed an oral exam in physics. The same thing happened to a number of Jewish applicants, with the same few examiners. It was 1965, a rather tranquil time in the former Soviet Union. I don't think that the examiners had any official instructions about whom to admit. They just followed their hearts. Nonetheless, the famous Moscow mathematician Alexander Semenovich Kronrod let everyone know of this circumstance, and somebody told me that the news had reached Gelfand.

Calling a Corresponding Member of the Academy of Science without any prior introduction was a severe violation of the Soviet code of conduct. But my parents were so desperate that my father dared to call Gelfand, who of course did not know him. After hearing the story, Gelfand calmly replied, "Let the boy go to the Pedagogical Institute (a sort of teachers' college). If he is good enough, he can also attend lectures at the university." I got the same recommendation from Kronrod, who also promised to supervise my studies in mathematics, and I followed this advice.

Kronrod (the last and perhaps most beloved student of N. N. Luzin) was a "problem solver". He did not like theories and was not a fan of modern mathematics. Following an old Moscow tradition,

Vladimir Retakh is professor of mathematics at Rutgers University. His email address is vretakh@math. rutgers.edu. 


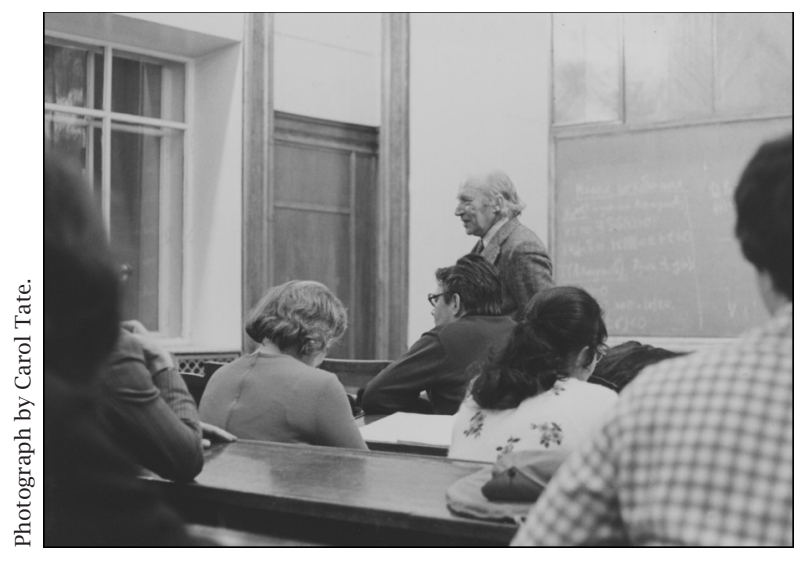

At the Monday night seminar.

I spent my first semester on problems in real variables, and in my second semester I was lured into seminars at the Moscow State University.

At one point Kronrod caustically asked me, "So what do you understand there?" "Not much," I confessed. Kronrod shrugged his shoulders: "Then try the Gelfand Seminar. If you go to mathematical seminars just to pray, you should do so in the main synagogue." So I started to attend the Seminar.

Gelfand's Seminar has already been described in many places by both participants and nonparticipants. Surprisingly, these descriptions often differ. There is not even agreement about the official starting time for the Seminar. I think that Simon Gindikin is right (he has given, in my opinion, the most accurate description of the Seminar): the official time was 6 to 8 p.m. But in fact, the seminar would start somewhere between 7 or 8 p.m., or even later, and go until 11 p.m. or so. Once or twice per semester Gelfand would start the seminar before 7 p.m. and then tease the latecomers.

At the seminar I was immediately overwhelmed by Gelfand's erudition and, at the same time, by the way he swooped down on the participants and speakers. Only a few, including Western foreigners and a grandson of A. N. Kosygin (the Soviet prime minister at that time), were shielded from Gelfand's barbs. One of my advisers claimed that in fact Gelfand interrogated potential speakers in advance for hours and then demonstrated his pseudo-improvisations in public. I think the truth was a little bit of everything. Gelfand could also choose a speaker out of people currently present at the seminar without any warning.

From time to time Gelfand would formulate absolute truths at the seminar. For example, one of his most famous statements was "Everything is representation theory." Later I understood that such absolute truths were in fact relative: Gelfand's truths depended heavily on the current situation, and their internal contradictions just created additional drama. Forty years later during a discussion of some noncommutative algebra problems, he changed this famous statement to "Nothing is representation theory".

Once Gelfand started the seminar with a poll of the distinguished participants Graev, Kirillov, Vishik, and others (they all sat together at the front of the room): "Do you know derived categories? No? How can you do any mathematics without it?" After a few years the pendulum swung in the opposite direction. During a talk on orthogonal polynomials (at which only the senior people paid any attention to the speaker), Gelfand threw out the phrase: "Youngsters are the most conservative people in the world; they always know what is right and what is wrong."

As I already noted, both speakers and participants were mercilessly ridiculed by Gelfand. However, victims could count on moral support from others. Gelfand's jokes were not considered a stain on one's reputation in any way. Rather, for a young person to be a target of Gelfand's sarcasm was a sign of distinction.

It was clear that foreigners coming to the Seminar considered it a highly exotic adventure. I remember a talk by Lipman Bers. He mentioned a theorem by Maskit and added, "I am proud that Maskit is my former student." Gelfand reacted immediately, "You cannot say 'my former student'. This is like saying 'my former son'." This was not a linguistic, but rather a cultural difference: Gelfand always saw himself as a father figure to his students and collaborators.

Gelfand's team always included both permanent and transient members. The most long-term collaborator of Gelfand (for almost sixty years) was M. I. Graev. Some of the team members would get well-posed problems, while others participated in discussions of rather vague ideas. In my own case it was often enough for Gelfand to ask, "Can we do something in this direction?"

While working with the team, Gelfand's only permanent motto was "I ask only simple questions." His other reactions were sometimes unpredictable, from "Why are you trying to adjust our project to your own interests? You do not see the big picture," to "I gave foolish advice and you just blindly followed it. It is enough to have just one fool in our company and it's me in this case."

After 1970, with the beginning of emigration from the Soviet Union, Gelfand's team started changing more radically. Kazhdan, I believe, was the first to emigrate. Others followed his example. In my opinion, the greatest loss for Gelfand himself, as for all of us, was the departure of Joseph Bernstein.

Emigrants at that time disappeared completely behind the iron curtain, and we had a feeling that 
they were lost forever. It was hard. We basically did not have any social life outside of mathematics. Our collaborators were usually our best friends, with whom we discussed everything: mathematics, politics, books, our personal lives, etc. Quiet and soft-spoken Bernstein was open to everyone, especially young mathematicians. He would listen to their vague and sometimes contradictory ideas and then often put them into brilliant and short statements.

The leader of the last Moscow team was Andrei Zelevinsky. He suggested to Gelfand that I be invited to work on their projects. Gelfand started our "negotiations" with a frontal attack. "Well, you are doing some homological algebra but we already have Beilinson for that. If you are going to work with me, you have to start from scratch. In medieval times painter's pupils worked for years just preparing paints for the master. Do you know what a hypergeometric function is? No? Very well, you can work with me on hypergeometric functions."

After a few days Gelfand changed tactics. He asked me to open the celebrated handbook of Bateman and Erdelyi and point out the formulas I liked. He reacted to my choices quite positively: "Well, you have some taste. Why were you so interested in that abstract nonsense?"

Mostly, I worked with Gelfand in his apartment. The routine was almost always the same: I would do long calculations in my notebook while Gelfand talked on the phone with an endless stream of people. From time to time he would look over my shoulder to discuss my results.

One day the routine was broken. A son of Anatole Kouchnirenko was hit by a truck while riding a bicycle. In such situations access to the right hospital and the right treatment was a question of life or death. Despite official Soviet propaganda, such things depended heavily on people's connections, influence, bribes, etc. Gelfand called up one physician after another: "Can you help? What advice would you give? Which is a good hospital? Well, Doctor N. has a different opinion. Why? Is N. really good? How do you rate him in comparison with Dr. M.? And how would you rate yourself? OK, can we start a joint project together?"

At the end of the day the situation was somehow defused and Gelfand returned to mathematics. However, the medical discussion left some residue. "Do you understand the difference between Arnold, Manin, and me?" Gelfand asked suddenly. "They are great coaches: they take talented students and train them to be Olympic champions. I can do all this, too, but I can also simply be a physiotherapist."

In the summer of 1988 or 1989 Gelfand lived with his daughter in a boarding house of the Academy of Sciences in Zvenigorod, and we rented a summer house in Kratovo, not far from Zelevinsky, Feigin, and Fuchs. The trip to see Gelfand was rather long: a train, a subway, then another train, then a bus. At the end of the trip I was pretty exhausted. So Gelfand suggested that we start something simple, such as looking for a good theory of noncommutative determinants. The only hint I got from him was that the theory must be based on Cramer's rules. At Rutgers, 1993. Gelfand had been asking about noncommutative determinants every semester since my sophomore year and my friends would always shrug their shoulders: "The old man is losing his grip. Who cares about such things now?"

At the boarding house, Gelfand lived in a tiny room. There was only space for two beds with their nightstands. We would kneel, with our notebooks on the beds, writing our formulas, and Gelfand would laugh like a happy child: "You just look at these formulas; they tell us what to do by themselves. How nice!"

We continued the game with formulas in Gelfand's kitchen in Moscow. Once a government official phoned Gelfand. He complained that his thirteen-year-old son hated mathematics and asked Gelfand for advice. I expected to hear a cascade of Gelfand's jokes, but he was dead serious. He asked the boy to pick up the phone and said, "I will give you just three problems: multiply one by one, one by negative one, and negative one by negative one."

The teenager gave the correct answer to the first two questions and then stopped. "That's great," Gelfand said, "you already know two thirds of all mathematics; you just need to try a little bit to get the rest of it". It was the best lesson in pedagogy I ever had.

My extended family emigrated to the U.S. in 1993. I spent a year as a visiting scholar at Harvard and Rutgers and then got my first teaching job at Oklahoma State University. I was almost scared to death at that time: my knowledge of the American Midwest was limited to O. Henry's stories, and among Russians there circulated a lot of terrible tales about American students.

As usual, Gelfand defused the situation: "Are you a professional or not? As a professional you must be able to teach at elementary school, to give talks interesting to Harvard faculty, and everything in between. Just one piece of advice: make your 
students comfortable in your classes-one cannot teach without this."

After spending a year at Oklahoma State University and another at Penn State University, I returned to Boston. My wife and I rented a small apartment near Harvard Square. A memorial conference for Garrett Birkhoff was scheduled on April 1st of that year and Gelfand was invited as a keynote speaker.

Gelfand came to Boston a few days early, and we spent this time preparing his talk on lattice theory. Unfortunately, a huge snowfall was expected in Boston right before the conference and the organizers at Harvard suggested cancelling the event. Many interested people would not be able to be there, the audience might be sparse, and so on. Gelfand surprised them by insisting that the show must go on under any circumstances. After all, no one worthy of being in the audience would miss it because of a little snow.

Gelfand's interests were at once intense and wideranging. Perhaps the most remarkable illustration of this is what happened on that snowy day he spoke at Harvard. To make the morning commute easier, Gelfand had spent the night in our apartment on a small futon in the living room. During our breakfast on April 1 my wife offered him some eggplant. "It is good", Gelfand said, "but the way you cook eggplant is totally wrong. I will teach you how to do it."

At that point I knew what might happen and had to act to prevent a cooking lesson that might last several hours. I pleaded, "It's late." In fact we started on our way through the snowdrifts.

Gelfand's talk, scheduled for one hour, lasted about two hours. Actually, he wanted to continue, but the listeners began to be restless. After the talk Gelfand approached me: "Do you understand why I agreed to come? I did not know Birkhoff. It is all about lattices. Maybe they can replace category theory, which is too rigid."

We never returned to this subject, and in a few months I left Boston for Arkansas. Gelfand did not call me very often, just two or three times a day. The first call was usually at 8 a.m. After two years I started my tenure at the same university as Gelfand and the number of his everyday phone calls doubled.

\section{Acknowledgment}

Many thanks to Mark Saul and to my Rutgers colleagues whose remarks greatly improved the initial version of this story.

\section{Serge Tabachnikov}

\section{Gelfand's School by Correspondence}

This note concerns a major contribution of I. Gelfand to mathematical education: the School by Correspondence for high school students at Moscow State University, founded by Gelfand in 1964 and commonly known as Gelfand's School.

The first half of the 1960s was a relatively liberal time in the history of the former Soviet Union. It was also the beginning of space exploration, and the general excitement generated by Sputnik extended to the exact sciences, including mathematics. This was the time when special high schools for physics and mathematics appeared in many large cities of the country. Let me mention two notable examples. The first is the Boarding High School No. 18 at Moscow State University, founded by A. Kolmogorov in 1963 for talented students from across the country. The second is the famous Moscow High School No. 2. Many well-known mathematicians, now working in various countries, are alumni of these and other similar elite schools.

Gelfand's School reached out to a much broader population of students, and its approach was very democratic: the goal was to provide a quality mathematical education to motivated and talented students, mostly from smaller towns and rural areas, who did not have access to specialized mathematical education available at major scientific centers. For example, as a matter of principle, Gelfand's School would not admit students from Moscow. The education in Gelfand's School was free.

\section{Structure of the School}

Gelfand's School was complementary to the school curriculum (which was the same in all schools in the USSR) and covered the last three years of high school. Unlike the common practice in this country, talented and motivated students were not accelerated through the curriculum but rather were offered a substantial enrichment and an in-depth study of the familiar "school mathematics".

Let me describe the school's mode of operation. Every student received, roughly once a month, a brochure covering a particular topic. These booklets contained some theoretical material, numerous examples of problem solving, and a test, usually consisting of two parts: mandatory and optional (each having a dozen problems or so). The student worked on this material for about a month, culminating in writing detailed solutions

Serge Tabachnikov is professor of mathematics at Pennsylvania State University. His email address is tabachni@ math.psu.edu. 
to the test and mailing it to Gelfand's School at Moscow.

There the tests were graded, mostly by teaching assistants recruited from undergraduate and graduate students of the Faculty of Mathematics of Moscow State University (it had a large population of students, with an incoming class of about 500, and offered five years of undergraduate studies). The ratio of TAs to students at Gelfand's School was about 1:10; ideally, a group of students from the same town or the same school was assigned to the same TA. To ensure quality, grading was multilayered: TAs were organized in groups, each group had a leader who cosigned each graded test and was personally responsible for the quality.

In fact, the word "grading" is not quite appropriate: the main goal was to teach the students, rather than just to assign a grade for their test. A typical work, sent back to the student, contained numerous remarks on the weak and strong points of the work, written in the margins, and oftentimes a detailed overall review of the progress of the student. Ideally, the same TA was responsible for the same student during his or her three years of education at Gelfand's School.

In its heyday, Gelfand's School had dozens of branch schools based at regional universities and pedagogical institutes. These branch schools had a similar structure; they supplemented the educational materials from the central school with those of their own.

\section{The Program}

The curriculum of Gelfand's School changed with time, but there was a hard core of topics and textbooks from the early days on. First of all, there were the classic books [1] and [2] (I refer to the English translations, not the Russian originals), written in 1964, that is, for the very first class of the school. They were followed by [5] and later by [3] and [4]. It is refreshing to compare these slim-yet very substantial-books with numerous bloated and inflated textbooks that are, unfortunately, so common! For example, The Method of Coordinates [1] has less than ninety pages, including numerous figures. Its last section concerns the geometry of the 4-dimensional cube; the section culminates with the problem of describing the family of 3-dimensional sections of a 4-dimensional cube, orthogonal to its main diagonal; this problem was discussed in detail.

Let me mention some other topics that are traditionally included in the curriculum: combinatorics, arithmetic of integers, polynomials, word problems, areas of polygons, equations and inequalities, complex numbers, logarithmic and exponential equations, space geometry, series and limits. Some topics were designed for more advanced students and were optional, for example, introduction to game theory (the title of the brochure was "Instructive games").

It is worth mentioning that some of the as-

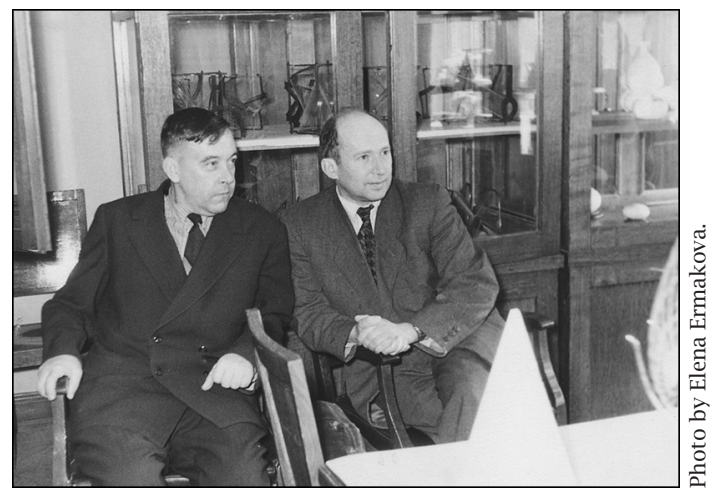

With N. V. Efimov, 1968. signments, especially in the last year of study, were designed to prepare for the entrance exams to universities (which were highly specialized; for example, at a faculty of mathematics, a student had to take four entrance exams: written mathematics, oral mathematics, oral physics, and an essay).

\section{Authors, Personnel, and Teaching Assistants}

A brief look at the references to this memoir shows that I. Gelfand was a coauthor of most of the books that made up the backbone of the educational material of the school. Gelfand attracted many a talented author to this work: E. Glagoleva, V. Gutenmacher, A. Kirillov, A. Shen, E. Shnol, A. Toom, N. Vasilyev, and others. Most of the authors were professional mathematicians, in some cases very prominent ones (A. Kirillov). Many brochures for the school were also developed by members of the school staff.

Let me say a few words about the firstand so far the only-director of the Gelfand School, V. F. Ovchinnikov. I. Gelfand had a rare gift of choosing unique people for his "teams"; V. Ovchinnikov was a perfect choice for the director. He was the founding principal of the Moscow High School No. 2 for physics and mathematics that was mentioned above. ${ }^{1}$ As a curiosity, let me mention that there was a law in the former Soviet Union that prohibited the same person to be a director of more than one organization simultaneously; as an exception, the appointment of Ovchinnikov as the director of Gelfand's School was signed by the Soviet Prime Minister A. N. Kosygin.

The staff of the Gelfand School consisted of six to ten teachers and program coordinators and about the same number of administrative assistants. Some of the former were previously

\footnotetext{
${ }^{1}$ The excellence of this school was not limited to physics and mathematics: literature, history, and other "ideological" subjects were taught exceptionally well by a team of brilliant teachers. For its students, the school was indeed an oasis of freedom. This eventually attracted the attention of the authorities, leading to a crackdown on the school and the firing of the principal and many teachers.
} 


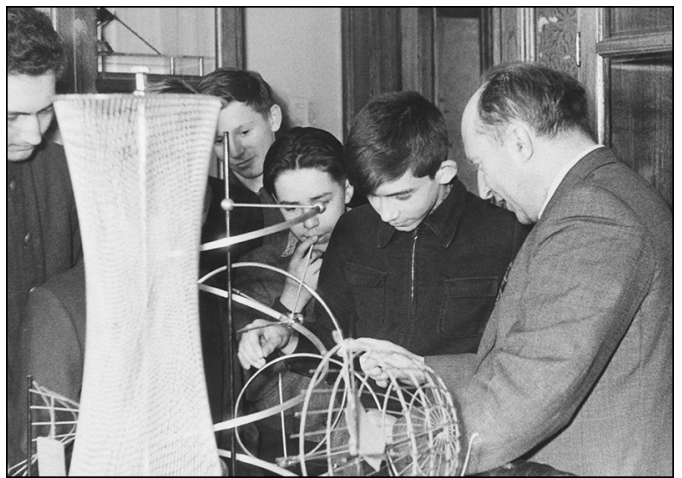

Explaining geometry to 8th graders, 1968.

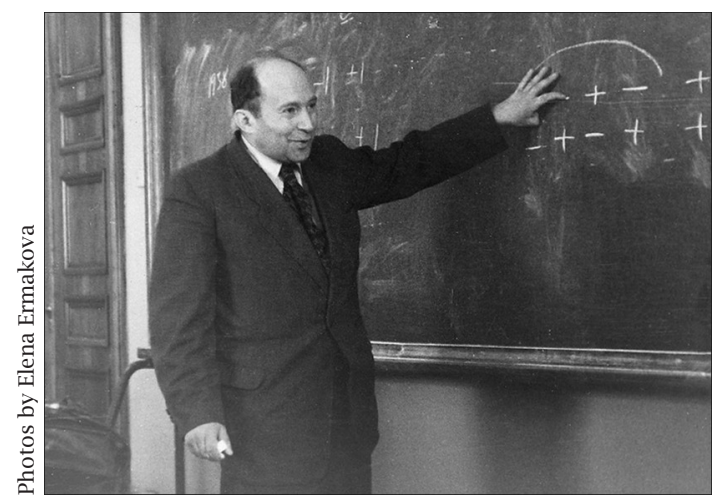

Explaining solutions to Olympiad problems, 1968.

teachers of mathematics at School No. 2, whom Ovchinnikov invited to work at Gelfand's School. As to the latter, most of them were workstudy students of Moscow State University. The author of this note worked at Gelfand's School in 1979-1988 (in particular, combining this full-time job with graduate studies). One of the responsibilities of program coordinators was to run a special training session for teaching assistants where these students were introduced to the next topic in the curriculum of the school and were prepared for the next grading cycle.

Many hundreds of undergraduate and graduate students of mathematics of Moscow State University served as Gelfand School TAs. Every Soviet student was supposed to do some "service". The nature of these "services" varied; for example, one of them was helping the police to patrol the streets (this was not a very popular job). In contrast, teaching assistantship at Gelfand's School was a desirable and prestigious service, so the school had no problem recruiting the necessary number of TAs. Many very well-known mathematicians served as teaching assistants in their undergraduate and graduate years. To represent three different generations, let me mention just three names: Mikhail Shubin (Northeastern), Victor Vassiliev (Moscow), and Maxim Kontsevich (IHES). Many teaching assistants were themselves alumni of Gelfand's School (there were years when close to a quarter of the incoming class at the Faculty of Mathematics of the Moscow State University consisted of graduates of Gelfand's School).

\section{Students}

To be admitted to Gelfand's School, a student needed to pass a written entry exam (the first class of 1964 consisted of 1,472 students selected from more than 6,000 applicants). The total number of students of the school over its forty-six years of work well exceeds 200,000. The majority of these students continued their education at good universities leading to careers in mathematics, science, and technology. I am not aware of any comprehensive data on the graduates, in particular, on those who became mathematicians. Let me just mention one notable example: Edward Frenkel (UC Berkeley) was a student at Gelfand's School in the early 1980s.

Along with individual students, Gelfand's School had "collective students". A collective student was one of a group of students from the same class that worked under supervision of their teacher (usually this was an after-class activity, akin to a math club). It was up to the teacher how to organize the work of this group; what it shared with an individual student was the same assignment and the same test. One collective student produced a single test which was graded the same way as those of individual students. An additional bonus was that the teachers who participated in this program substantially expanded their mathematical and pedagogical horizons; in effect, this was a form of continued education for high school teachers.

\section{Gelfand's School Today}

Today Gelfand's School is alive and well. It is now called an "Open Lycée", having eight departments that, in addition to mathematics, offer courses in biology, physics, history, economics, chemistry, philology, and law. The full course in mathematics now spans five years. Many things have changed in Russia (including the name of the country), but Gelfand's School has survived all the disturbances and cataclysms, and it continues to provide high quality mathematical education to a large number of students across the country.

\section{Another Gelfand Story}

Let me finish with a Gelfand story that concerned me personally. In the mid 1980s, I submitted a proposal to my supervisors at Gelfand's School on how to improve the geometry courses that we offered at the time. This was a rather bold and not very well-balanced proposal; anyway, it ended up on I. Gelfand's desk. One day, my telephone rang. It was Gelfand speaking. "Do you want to hear a joke?" he asked. The joke goes like this: A crow sits on a branch of a tree. A rabbit runs by. "Hello, crow, what are you doing?" "I am showing off." "May I join you?" "You are welcome." So the rabbit climbs the tree and sits next to the crow. Then a fox runs by, asks the same question, and also joins them. So does a wolf. Finally, a bear walks by. "May I join you?" the bear asks. "Please do." When 
the bear sits next to the rest of the animals, the branch breaks and all the animals fall down except the crow, who flies and cries, "Before showing off, learn to fly!"

Gelfand continued to explain to me that, so to speak, I wanted to feed the students with pastries and candies whereas what they really needed was whole grain bread. I remember this lesson to this day. ${ }^{2}$

\section{References}

[1] I. Gelfand, E. Glagoleva, and A. Kirillov, The Method of Coordinates, Birkhäuser, 1990.

[2] I. Gelfand, E. Glagoleva, and E. Shnol, The Method of Coordinates, Birkhäuser, 1990.

[3] I. Gelfand and A. SHen, Algebra, Birkhäuser, 1993.

[4] I. GELFAND and M. SAuL, Trigonometry, Birkhäuser, 1999.

[5] V. Gutenmacher and N. VAsilyev, Lines and Curves, Birkhäuser, 2004.

\section{Mark Saul}

\section{Gelfand at 92}

In October 2005 I got an email message from a woman with a Russian name whom I didn't know. I immediately knew that it was actually from I. M. Gelfand and that the person writing was one of his many minions, on whom he relied for communication.

"Professor Gelfand would like to speak to you," it read, coldly. But I knew there was more to it than that. Professor Gelfand and I had spoken every six months or so, and I had last seen him two years ago. But it was I who always called him, not the other way around. Something's up. Something's wrong.

A phone call verified this. Gelfand was in the hospital and wanted to speak with me. It must be serious. Maybe he's thinking that it's his time, and he wants to say goodbye to his friends and colleagues. So I called around to others who knew and worked with him. This took awhile, and by the time I reached someone, it was to find out that Gelfand was back home. He had stumbled and became concerned about his health, so went to the hospital, from which he was now released.

I called Gelfand at home. His voice was a bit weaker than before, but still clear. His hearing, too, had deteriorated a bit. After repeating everything twice, I was handed over to yet another minion, who spoke only Russian, and I had to repeat my

\footnotetext{
${ }^{2}$ Eventually I wrote a little book on polynomials for Gelfand's School. This book is still in use there.

Mark Saul is the director for the Center for Mathematical Talent at the Courant Institute of Mathematical Sciences. His email address is mes37@nyu. edu.
}

responses in that language. Gelfand asked when I could come see him-again not typical of him.

This was all in mid October. My schedule and his did not allow us to meet until some weeks later. It had been raining for a week, and traffic was snarled. So I was two hours late. No matter. I came to the door of Gelfand's nondescript suburban home and was greeted by Irina, the telephone minion, who looked after him when no one else was home. I was ushered in and sat down at a small table just outside the kitchen. On the table was a pile of folders, obviously work in progress. Some separate sheets of paper bore equations, symbols, and notes. Three softcover Russian books lay nearby.

"One minute," Irina said, and left the room.

But it was almost five minutes that I waited. After looking at every object in the room several times, objects that were not new to me, I heard a quiet, rhythmic bump-bump, bump-bump, bump-bump. Before I could see what it was, I knew what it was. It was an old man with a walker, making slow but purposeful progress around the corner of the corridor and towards me. It was Gelfand.

He sat down in a chair with a well-worn cushion and fastened his still bright blue eyes on me. He was very glad to see me, very glad to talk. He talked slowly at that point. His hands shook like birds fluttering against the bars of their cage. His thoughts quickly outgrew the prison of his mind-an old struggle, but now they were caught in the prison of his body - a new one.

He was still thinking, his mind roving widely over an intellectual landscape while his body remained in that old chair with its old cushions. He pointed to the three books recently published in Moscow. Two bore his name (as well as those of coauthors). A third was by a former student, with a handwritten message to Gelfand on the title page, thanking him for all he had given the author. The books were about applications of mathematics to medical diagnosis. Gelfand slowly explained to me some of the issues. His eyes blazed with energy, just as I had remembered them. But now I had to look closely to see his face reflecting the joy of discovery, as it used to. For him, it was more than simply a sense of accomplishment. It was a joy in the knowledge itself, as the pride of a parent can be for the child itself and not just for the parent's own role.

I remember a conversation of about six years ago, one September. I had gone on vacation that summer with my family, while Gelfand was in France, working with some European mathematicians.

"Did you have a good summer?" I asked. "Did you get to relax?"

"I didn't have time to relax. I learned many new things," said the 86-year-old winner of the MacArthur, Kyoto, and Wolf prizes (not to mention 


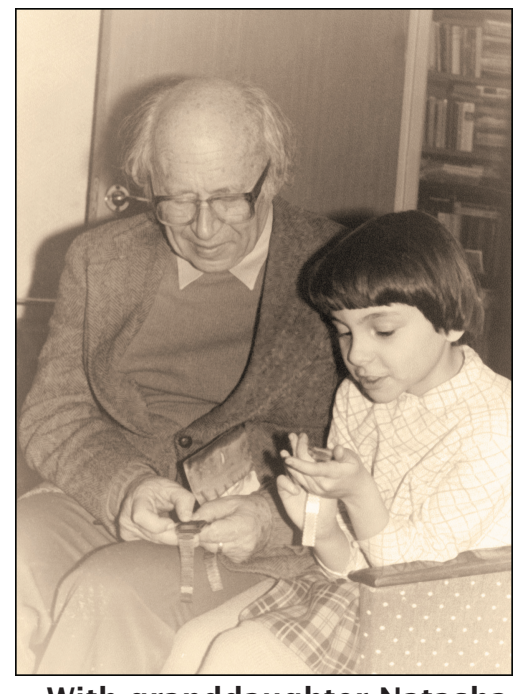

With granddaughter Natasha, into practice. It dawned on

1982. me that this was exactly my role when we worked on educational issues together. It was a collaboration, but the freshest ideas, and the most basic ones, were usually his. He was already an old man, even then. His mind, however, was a young one, even now.

Yes, he took pride in the accomplishments of his students. But the relationship was not the usual one between teacher and student. He taught them how to think, how to investigate things mathematically. But he remained with them, it seems, even on the next lowest level-the level not just of processing ideas, but of the particular ideas themselves. His mind overflowed with them, and he seemed to have had the ability to surround himself with people who were worthy receptacles, who ensured that the abundance of ideas did not fall on parched earth.

We spoke about what he might do to support education and how I might contribute to his continuing work. We talked about our colleagues' work in America. He would not talk about the past, although I was curious. He mentioned that one Russian colleague did not know how to deal with the American system as well as he did. This colleague was only seven years old, after all, when Stalin died. I tried to ask him how his experiences under Stalin helped him adjust to America, but this topic did not interest him.

I admired some new paintings which had appeared on the wall. They were the work of his daughter, who was studying art. He beamed and rose. He showed me some more work. Haltingly, using the walker, he led me into his bedroom, where the work was displayed. Irina, hearing him move, immediately came downstairs, following behind him lest he fall. Various bits of hospital apparatus lay around the bed. Life was more complicated for him than he let on.
When we got back to the living room, Gelfand turned the conversation to our trigonometry book. "We must revise it," he commented. I asked what needed revision. He replied immediately, "The Pythagorean Theorem. The proof. It's wrong."

I asked for more details. His hands fluttered over to a pencil and began drawing. His lines were wiggles, like the outlines of the aged elephants in the Babar books. But I knew what he was drawing.

He drew a large square. He proceeded around its perimeter, putting a point on each side, a short distance from each vertex. I knew, because I knew this proof, that the short distances were meant to be equal. He connected these points, forming four right triangles and a square inside. He wrote down $(a+b)^{2}$. I finished the diagram, marking the short segment " $b$ " and the remainder of each side " $a$ ". Then I marked the hypotenuse of each triangle, which is a side of the inner square, with " $c$ ".

"Yes," he said, and wrote down "... $c^{2}+$ $4(a b / 2) "$. The area of the big square was equal to the area of the inner square plus four times the area of one right triangle. Expanding, this proved the theorem. I smiled. I knew this proof and so did he, but somehow we used a more complicated one in the trigonometry book.

"So this is how we must revise the book," I said.

"Yes," he said and sat silently for a minute. He often fell silent during a conversation, sometimes for many minutes, to think about something. One learned patience with this seemingly antisocial behavior. Sometimes, after the silence, he would walk over to the phone and make a call or read some email or take a book from the shelf and show me a poem of Pasternak. His mind often behaved like a magnificent wild animal, which he was trying to use as a beast of burden. Eventually the flow of the conversation would return, but one never knew how or when.

My patience eventually paid off. He broke the silence: "It is wrong."

I confessed that I didn't see the error. He smiled a bit, and his eyes lit up. He enjoyed this intellectual cat-and-mouse game, a game which betrayed the art of a master teacher. I knew what was coming. He would tell me as little as possible until I got the idea myself.

I knew, but at the same time I was concerned. How could this classic proof be wrong? Was his mind getting old after all? I suppressed the thought. If it was right, I would know soon enough. If it was wrong, I would learn something. The wager was an easy one to make.

I was wrong, of course. His hands again took up the pencil and drew a diagram which I eventually resolved into two right triangles symmetric about a line, with the same hypotenuse. "When are two triangles congruent?" he asked me. 
Uncharacteristically, he answered himself, "When they can be made to coincide." He didn't know the English word "coincide", so he used the Russian. With a gesture whose irony would unfold with the dialogue, I agreed, placing my right hand, fingers extended, exactly over my left.

"These two triangles cannot be made to coincide. You must reflect one to get the other. There are two definitions." I knew what he was saying, but not why he was saying it. We had talked years ago about orientation in the plane and how areas of polygons can be given a sign according to the orientation of their perimeters. The subject had arisen with the discussion of Hero's formula, and we had decided not to include the issue of signed areas in the trigonometry text. But what does this matter have to do with the proof at hand?

I didn't understand, and told him so. The four triangles in the diagram all had the same orientation. Even if you didn't allow for reflections, they could be made to coincide. You didn't need to “flip". Didn't he see this? I knew better than to ask Gelfand this last question. But I harbored a mental reservation. Happily, I found that I still had some patience.

Gelfand had more. He just looked at me. I thought he didn't understand. But of course the shoe was on the other foot. "Look," I said. "You trace this triangle clockwise. Then you trace the next one clockwise. A rotation brings one onto the other. There's no need to flip."

Gelfand was not impressed. He merely asked, "Rotation about what point?"

The question was too easy. There was some ulterior motive for it. "Around this one." I indicated the center of the square.

Then suddenly I saw what he had seen, and I gasped. The triangles indeed had the same orientation. But if you trace the triangles in a clockwise orientation, the four hypotenuses form a square with a counterclockwise orientation.

!!!

"So the areas are equal only in modulus. We have to account for this in our book." He said a few more things, but the words were inconsequential in comparison with the lessons, both mathematical and pedagogical, that I had learned. The teacher in him knew that I would eventually figure things out and that this process would do me more good than if he had told me what he was thinking. This was his gift to me: a gift of knowledge, a gift of patience, a gift of trust. He could have shown me his idea directly. I would have been duly impressed with the insight and would have let others know. Instead, he let me discover the insight-and thus demonstrated his gift both as a mathematician and as a teacher.
I began thinking about other dissection proofs of the Pythagorean theorem. Is there always this anomaly? Or is the problem with the particular argument we are using? I was thinking again about Hero's formula and the role orientation might play there. But it was 8:15, it had taken me three hours to get there through snarled traffic, and Gelfand was getting tired.

So we adjourned. I agreed to call and to do a few more errands for him.

The trip back was uneventful. The rain had stopped and the traffic cleared. That's all I remember about it because I was occupied by the picture of Gelfand at 92 , by the diagrams he drew, by the flaw in the proof, and by the art of teaching so beautifully laid out to me.

I am occupied still. What led me to that incredible insight? Was it Gelfand's question about the center of rotation? Or simply his silence, a communication in itself that there was something more to see than I had seen? In what did the act of teaching consist? These are not simple questions, and I'm not sure what methodologies will allow us to answer them.

There were more thoughts as I drove: Was it an act of courage for him to stay active like this? I wasn't sure it was. His experience might simply have been that of living, and thinking, and creating, as most of ours is of living, and breathing, and eating. But I can certainly count it a lesson in courage among the lessons I learned from Israel Moiseevich Gelfand that night. 